\title{
CONTRIBUTION TO THE STUDY OF THE PERFORMANCE OF MUSSELS IN CONCRETES FOR THE MANUFACTURING OF PARTS IN COMPOSITE MATERIALS
}

\author{
S. TAFRAOUI, A. TAFRAOUI, M. DAHMANI,
}

\section{ZAOUI \& A. CHAOUFI}

Laboratory of Reliability of the Mechanical Engineering, Kenadsa, Bechar, Algeria

\begin{abstract}
In the field of composite materials, the realization of prototypes of the mussels on which it manufactures the model in composite materials led to a phase very long and very expensive, particularly in terms of the state of the surface and geometric accuracy. It is important to have methods of experimental casting to ease and decrease the time of realization of a room in the composite material.
\end{abstract}

The search for simple methods with materials less expensive and little polluting allows the evolution of composite materials. It wants to use during this study a concrete ultra-high performance UHPC to achieve of molds for manufacturing operations and achievement of different parts in composite materials.

KEYWORDS: Molds, UHPC, Formulation \& Composite Material

Received: May 27, 2018; Accepted: Jun 17, 2018; Published: Jul 16, 2018; Paper Id.: IJMPERDAUG201852

\section{INTRODUCTION}

The composite materials have important assets compared to traditional materials. They provide many of the functional benefits: lightness, mechanical and chemical resistance, reduced maintenance, freedom of forms.

They allow increasing the length of life of some equipment thanks to their mechanical and chemical properties. They contribute to the strengthening of security thanks to a better resistance to shocks and fire; they offer a better thermal insulation and a good electrical insulation. They also enrich the possibilities of design by allowing alleviating the structures and complex shapes, able to fulfill several functions [1, 2, 3, and 6].

The composite materials are used to achieve new levels of performance. In effect, they have a geometrical structure specifically designed for their confer properties that their elementary constituents individually do not have, and enable them to fulfill many of the technical functions.

In each of the markets of application (automotive, construction, electricity, industrial equipment, aeronautics), these remarkable performances are at the origin of innovative technology solutions $[7,8,9]$

The obtaining of a part in the composite material is the result of the implementation of a process of manufacture appointed casting that is-determined on the basis of several criteria; almost all processes are the call to a mold whose definition and the constitution are a function of the technical implementation restraint [10, 11, and 12]. 
The role of the mold is to put in the form the laminate, it must therefore, be rigid and hard surface, the materials Most often used for molds are polyesters and epoxides in stratified and in concrete; the plywood or solid wood; the plaster; the aluminum or steel plate.

In this study perceive the implementation of mussels in UHPC concrete for the realization of parts in composite materials. This implementation can reduce the preparation time of the mold until the finished part is obtained, and lower the cost of ownership of the casting for the manufacture of certain parts in composite materials.

\section{MATERIALS AND METHODS}

Materials

Cement

The Cement chosen in this study is of the Portland type composed CPJ CEM II/b 42.5. It is consistent with the standard of Algeria NA 442.

\section{Additions}

The silica fume used in this work is a gray powder (quite dark) [19], and outcome of the manufacturing industry of the ferrosilicon. These chemical and physical characteristics are data respectively in Table 1 and Table 2.

Table1: Chemical Compositions in \% of the Materials Used [13, 14]

\begin{tabular}{|l|c|c|c|c|c|c|c|c|c|}
\hline & $\mathbf{S i O}_{\mathbf{2}}$ & $\mathbf{A l}_{\mathbf{2}} \mathbf{O}_{\mathbf{3}}$ & $\mathbf{F e}_{\mathbf{2}} \mathbf{O}_{\mathbf{3}}$ & $\mathbf{C a O}$ & $\mathbf{M g O}$ & $\mathbf{N a}_{\mathbf{2}} \mathbf{O}$ & $\mathbf{K}_{\mathbf{2}} \mathbf{O}$ & $\mathbf{S O}_{\mathbf{3}}$ & Loss at the Fire \\
\hline Cement & 22.50 & 2.00 & 2.80 & 67,30 & 0.75 & 0.19 & 0.19 & 2.10 & 3.00 \\
\hline Silica Fume & $>95.00$ & - & - & - & - & 0.60 & - & - & - \\
\hline Dune sand & 97.33 & 0.83 & 0.24 & 0.07 & 0.41 & 0.09 & 0.04 & 0.18 & 0.40 \\
\hline
\end{tabular}

Table 2: Physical Characteristics of Materials Used [13, 14]

\begin{tabular}{|l|c|c|c|}
\hline & Cement & Silica Fume & Sand of Dune \\
\hline Specific surface bet $(\mathrm{cm} 2 / \mathrm{g})$ & 3390 & 230000 & 115 \\
\hline Average dimension D50 $(\mu \mathrm{m})$ & - & 0.1 & 250 \\
\hline Actual Density & 3.16 & 2.24 & 2.65 \\
\hline Coefficient of water absorption $(\%)$ & & & 0.15 \\
\hline
\end{tabular}

According to the bibliographic research, and after the analysis physicochemical, the quartz sand of dune of the Western erg in the region of the south-west of Algeria is promising in the formulation of UHPC.

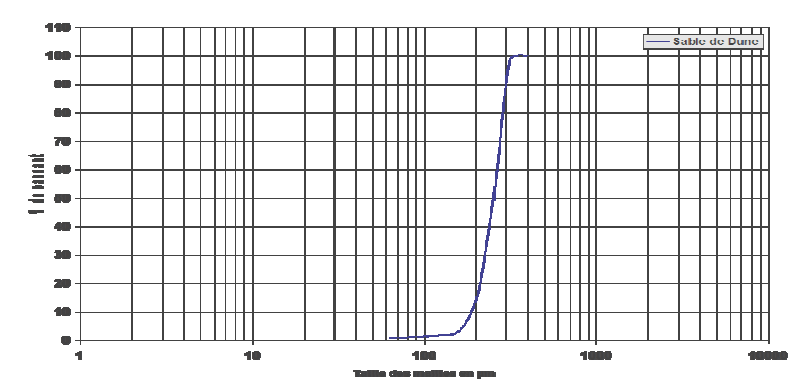

Figure 1: Particle Size by Sieving the Different Materials used [13, 14] 


\section{Super Plasticizer}

The super plasticizer top reducer of water use is consistent with the Standard NF EN 934-2 [4, 5].

The water used is of the drinking water from the network.

Metallic fibers in steel and synthetic fibers.

\section{Experimental Methods}

\section{Formulation}

The formulation of the UHPC is much more complex to highlight because of the number of parameters that between in-game (cement, sand, additions, adjuvant, fiber, water) and of their nature in relation to the formulation of a plain concrete. Most of the formulas of UHPC are currently designed in such a way as experimental.

The development of these formulas of BUHP is to determine the quantities of each component to respond to the specifications of these new concretes:

- A report E/C very low $(<0.2)$

- An increase of the compactness by optimization of the granular skeleton

- The employment of fine sand $(0.063 \mathrm{~mm}<\operatorname{Dmax}<2 \mathrm{~mm})$ in order to improve the homogeneity

- The use of the ultra fine

- The use of the crushed quartz in the case of a thermal treatment beyond $90^{\circ} \mathrm{C}$

- A metering in super plasticizer close to its dosage to saturation

- The use of metallic fibers to increase the ductility

On the other hand, the volume of dough must promote the flow of the concrete while reducing the cost of raw materials to this formulation.

The table 3 presents the formula after optimization of the granular skeleton and dosage in super plasticizer, from the dune sand, with or without crushed quartz (according to that the material will undergo a heat treatment beyond $90^{\circ} \mathrm{Cor}$ not), strengthened or not of steel fibers, with silica fume.

Table 3: Formulations of UHPC with Dune Sand $\left(\mathrm{kg} / \mathrm{m}^{3}\right)[14]$

\begin{tabular}{|l|c|}
\hline \multicolumn{1}{|c|}{ The Components } & $\mathbf{K g} / \mathbf{m}^{\mathbf{3}}$ \\
\hline Cement & 691 \\
\hline Siliceous sand & 759 \\
\hline Silica Fume & 172 \\
\hline Metallic fibers & 138 \\
\hline Superplasticizer & 22.0 \\
\hline Effective water & 187,3 \\
\hline Density $\left(\mathrm{kg} / \mathrm{m}^{3}\right)$ & 2399 \\
\hline E/C & 0.27 \\
\hline
\end{tabular}




\section{Mechanical Testing}

In this context, we will focus only to the mechanical behavior of this formulation of the UHPC, presented in the table3, through the study of their resistances in compression and bending $[15,16,17,18,20$, and 21].

\section{Resistance in Compression With and Without Thermal Treatment}

The results of the resistors in compression corresponding to the average value of 6 tests conducted on the two pieces of 3 prismatic tubes $(40 \times 40 \times 160 \mathrm{~mm})$ tested previously in compression. They are presented in the table 4 for the 4 deadlines of $1,7,14$ and 28 days are presented in the table 4.

Table 4: Resistors in Compression without Heat Treatment (MPa)

\begin{tabular}{|c|c|}
\hline $\begin{array}{c}\text { Time } \\
\text { (Days) }\end{array}$ & $\begin{array}{c}\text { Resistance of } \\
\text { Compression(MPa) }\end{array}$ \\
\hline 1 & 70 \\
\hline 7 & 124 \\
\hline 14 & 149 \\
\hline 28 & 169 \\
\hline
\end{tabular}

The results, obtained for the heat treatment to know a drying at $150^{\circ} \mathrm{C}$, are summarized in the Table 5 .

These resistors have been measured after a day of cooling, which corresponding to a deadline of 8 days after casting. These results show that the drying improves the resistance in compression.

Table 5: The Resistors in Compression with Thermal Treatment $150^{\circ} \mathrm{C}(\mathrm{MPa})$

\begin{tabular}{|l|c|c|}
\hline \multicolumn{2}{|c|}{ The Samples } & {$[\mathrm{MPa}]$} \\
\hline Not heat treatment & Rc28j & 169 \\
\hline With heat treatment at $150^{\circ} \mathrm{C}$ & Rce150 & 254 \\
\hline
\end{tabular}

\section{Resistance to Bending With and Without Heat Treatment}

The Table 6 presents the results of the mechanical tests of bending in function of the age of the material obtained for the FUPC studied according to the Standard NF EN 12390-5 [19]On tubes $(40 \times 40 \times 160 \mathrm{~mm})$, the resistances in bending are calculated from the maximum force applied by the press.

Table 6: The Resistors in Bending Without Heat Treatment (MPa)

\begin{tabular}{|c|c|}
\hline $\begin{array}{c}\text { Time } \\
\text { (Days) }\end{array}$ & $\begin{array}{c}\text { Flexural Strength } \\
\text { (MPa) }\end{array}$ \\
\hline 1 & 18 \\
\hline 7 & 24 \\
\hline 14 & 31 \\
\hline 28 & 33 \\
\hline
\end{tabular}

\section{Process of Molding}

It was sunk our concrete in the plastic mold carefully clean, without lubricant, see (Figure 2). After 24 hours in a room of $20^{\circ} \mathrm{C}$, the tools are unmolded and put in the water for 28 days. Mussels in the UHPC (Figure 3 and 4, 5) have a 
compression strength equal to $254 \mathrm{MPa}$, a flexural strength of approximately 45MPa, and a tensile strength of $15 \mathrm{MPa}$.

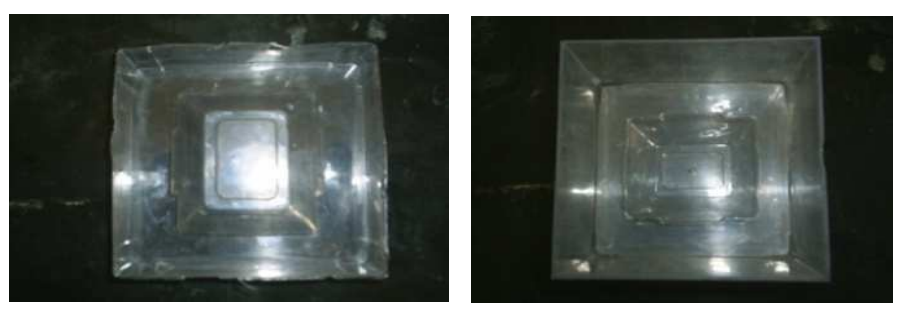

Figure 2: Plastic Molds


Figure 3: Mold 1 in Concrete



Figure 4: Mold 2 in Concrete

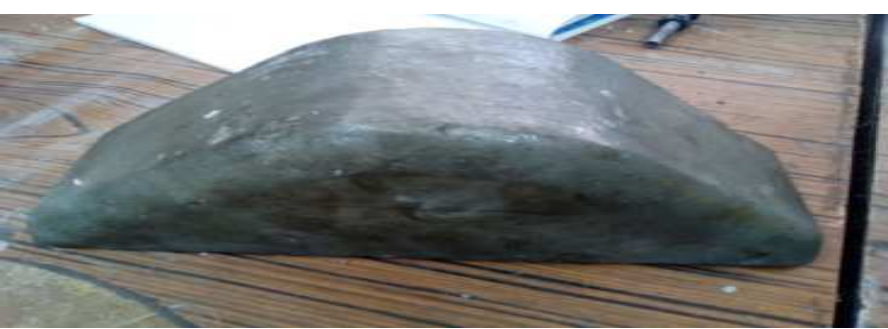

Figure 5: Mold 3 in Concrete

After you have completed the mussels in UHPC, we pass to the phase of molding in order to fabricate prototypes of parts in composite materials by using our mussels in UHPC.

It has chosen the contact molding which is a process allows realizing manually of unitary parts or small series.

\section{Composite Materials and Tools}

- $\quad$ The wax mold release

- Glass Cloth (mat of glass $300 \mathrm{~g} / \mathrm{m}^{2}$ )

- $\quad$ The polyester resin

- $\quad$ The hardener ECP 
- The gel-coat of finishing

- Diluent for the cleaning of paint brushes

- A round brush for the application of polyester resins

- A flat brush to move the wax mold release

- A flat brush for the application of the freeze- coat

- Gloves to protect the hands

- A scissors for cutting the fabric of glass

- A mask of protection

- Abrasive paper

- Sander

- $\quad$ Paint and dye

\section{Implementation for the Mold 1}

- We spend two thin layers of wax on the mold1 (Figure 6), we let dry the layers of wax filed during $10 \mathrm{mn}$.

- It cut pieces of the mat of glass, and after you have prepared the mixture polyester resin with the durssiceur, we take the flat brush and we spread this mixture on the mold1 then ask the first piece of fabric of glass (Figure 7) it applies therein and so on for the second and the third layers.

- After 9 hours of curing, a piece of composite material typical of the UHPC mold shown in Figure 8, Figure 11 is obtained.

- We once used the demolding wax we got the piece (Figure 9), and another time the Flicker as mold release (Figure 10) from where we spent a single layer of the latter on our counter mold.

After these results we have achieved several parts is it has obtained the same aspects that our mold.

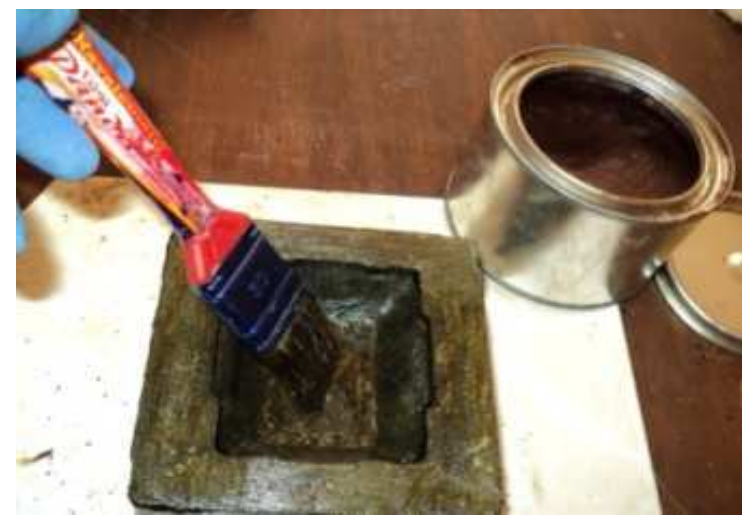

Figure 6: Application of Wax on the Mold 1 




Figure 7: Install MAT on the Mold 1

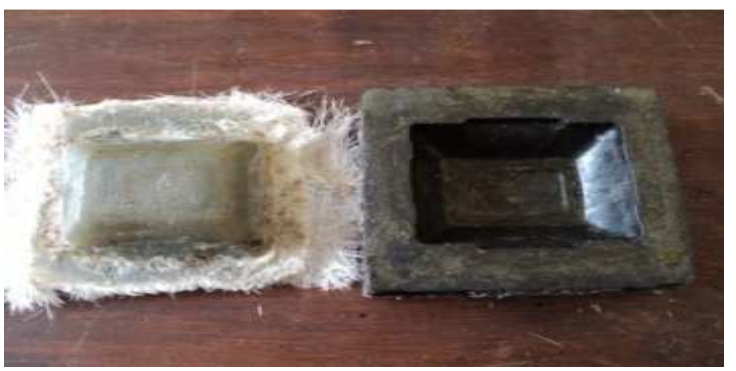

Figure 8: Model in a MAT of Glass obtained the Mold 1

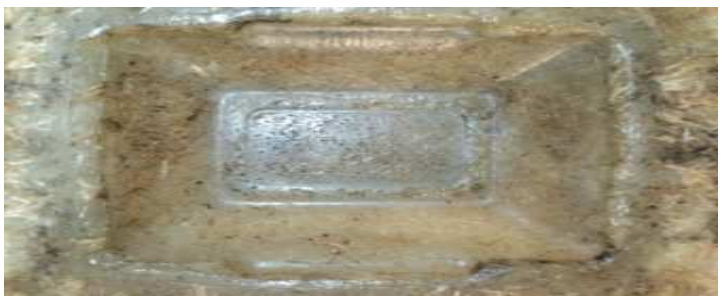

Figure 9: Model obtained (before Finishing)

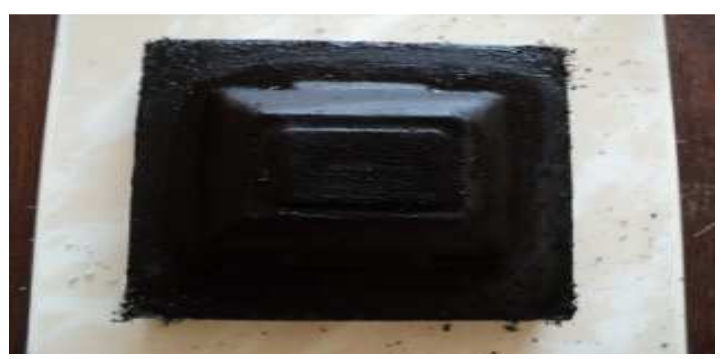

Figure 10: Against Painting Mold by the Flincotte
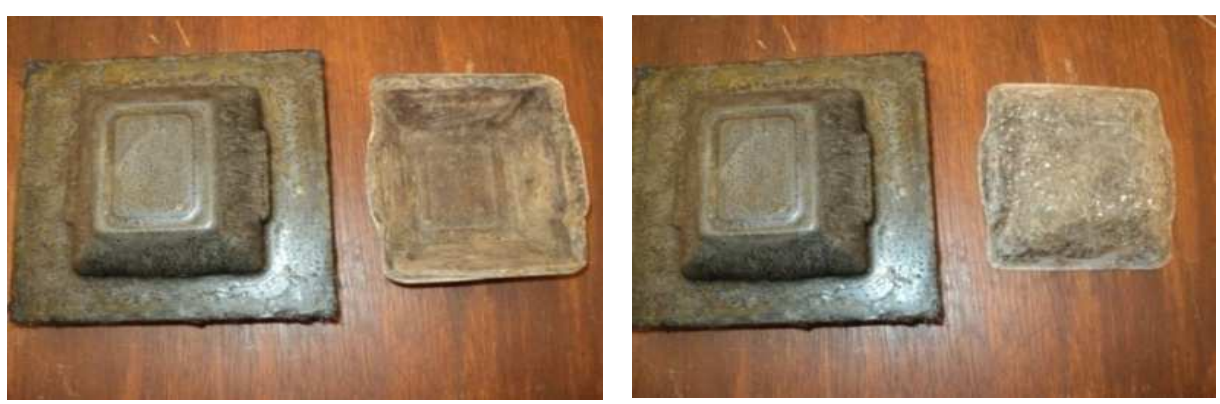

Figure 11: Models in the Mat of Glass Made by Molding to the Contact of Against Mold 1 


\section{Implementation for the Mold 2}

- It applying the steps of molding on the mold 2, and after several trials it was obtained of the parts in the Composite Material (Figure 12)which has the same aspects that our mold 2 and after each casting our mold has kept his state of the smooth surface.
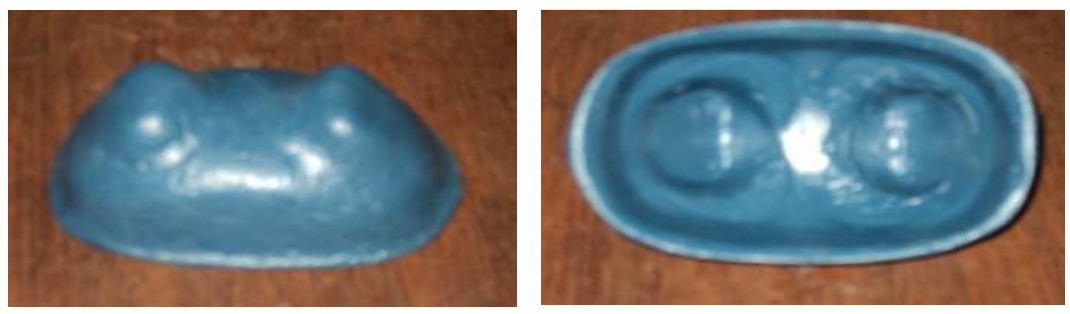

Figure 12: Model 2 Manufactured in Composite Materials

\section{Implementation for the Mold 3}

- It applying the same steps of molding on the mold 3, and after several trials, it was obtained of the parts in the CM (Figure 13) which has the same aspects that our mold 3.

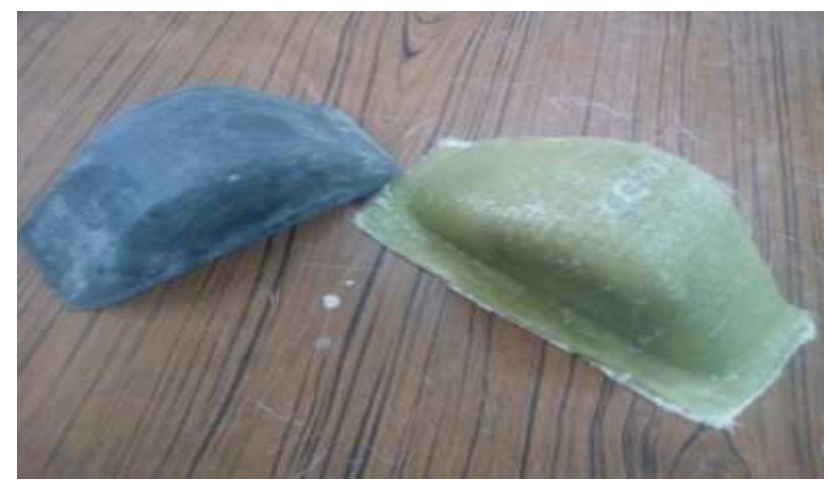

Figure 13: Model 3 Made of Composite Material

\section{RESULTS AND DISCUSSIONS}

After mold release, it was found that there was no tearing of the matter. All mussels carried out in UHPC give a typical footprint to parts of origins. After each casting, our mold has presented a very smooth surface and very clean without air bubbles with a roughness $\mathrm{Ra}=0.40 \mu \mathrm{m}$.

After formulated our UHPC, it has conducted a series of mechanical attempts or our UHPC to present a constraint of compression up to (254MPa) and a constraint of bending of (45MPa) with a pull of approximately (15MPa). The mechanical performance of this type of concrete gives him the opportunity to be exploited in the field of composite materials.

On the other hand, this UHPC has registered important values of porosity and absorption in the water $\left(0.2 \mathrm{~kg} / \mathrm{m}^{2}\right)$, a modulus of elasticity equal to $(55 \mathrm{GPa})$ and a coefficient of fish $(0.2)$, its expansion coefficient is equal to $\left(12 \times 10^{-6}\right.$ by $\left.{ }^{\circ} \mathrm{C}\right)$ [22]. The withdrawal is almost nil in the case of the UHPC treaty to $150^{\circ} \mathrm{C}$. 


\section{CONCLUSIONS}

The bibliographical study which focused on both composite materials and manufacturing processes, allowed us to better understand the scientific bases behind the development of these new materials and to know their properties of use as well as the importance of the choice of type of molding and tooling, especially the mold which has a direct influence on the state of composite parts obtained by molding, and on the cost of manufacture which influences the price of come back from these pieces $[14,15,16]$.

The use of the UHPC formula of Professor TAFRAOUI who managed to develop the dune sand to obtain an ultrahigh performance concrete that exceeds $200 \mathrm{MPa}$ up to $254 \mathrm{MPa}$ compressive strength and $45 \mathrm{MPa}$ flexural strength, for the realization of our molds or we dumped the geometry of these last ones in order to have different forms to realize in continuation of the different pieces in CM, of which we had smooth surfaces with perfect imprints, which is an important criterion for the successful molding of parts.

The choice of the process of transformation of the composite materials is guided both by the nature of the material (thermoplastic or thermosetting), the shape of the part to be produced, the targeted performances, and the production requirements in terms of quantity and rate.

Processes for processing high-performance composites are still manual or poorly automated. They are compatible with the production in small series of high added value parts (aeronautics, sports, and leisure, medical).

Contact molding and simultaneous projection are, in turn, manual processes suitable for the production in small series of parts, both in high-performance composites and in high-performance composites. This justifies our choice of contact molding for the realization of our composite material parts in our study.

In addition, the contact molding application on these molds initially gives Composite Materials parts that perform the same aspects as our UHPC molds with high performance and reduced molding cost compared to the used polyester or epoxy or steel molds with shorter lead times and costly machining.

Finally, we can conclude that it was initially possible to produce UHPC concrete molds for the manufacture of composite materials.

\section{REFERENCES}

1. M. Abdelyamine. Dynamic analysis free of plate's multilayer composite. Memory of magister, Mentouri, Constantine, 2009.

2. A. Chaoufi, A. Tafraoui, M. Zaoui, S. Tafraoui \& M. Dahmani. Research of the parameters of cut for the machiningof the new concretes. International Journal of Mechanical and Production, Engineering Research and Development (IJMPERD) ISSN (P): 2249-6890; ISSN (E): 2249-8001, Vol.7, Issue 6, Dec 2017, 321-332.

3. M. Zaoui, A. Tafraoui, A. Chaoufi, S. Tafraoui \& M. Dahmani. Therealization of thin sheets stamping tools with an economical material. International Journal of Mechanical and Production, Engineering Research and Development (IJMPERD) ISSN (P): 2249-6890; ISSN (E): 2249-8001, Vol.7, Issue 6, Dec 2017, 437-444.

4. Afnor, NF EN 934-2/A2. Additives for concrete, mortar and grout-Part2: additives for concrete- definitions, requirements, compliance, marking and labeling, AFNOR, April 2006.

5. Afpc-Afrem. Recommended methods for the measurement of quantities associated with sustainability, account of technical days PSAC-AFREM Sustainability of concretes, Toulouse 1997. 
6. S. Assié. Sustainability of autoplaçants concretes. Doctoral thesis, INSA Toulouse, Order No: 747, October 2004.

7. J. Baron, J. P. Ollivier. The sustainability of the concretes. The Presses of the National School of bridges and pavements, 1992.

8. O. Bonneau, M. Lachemi, E. Dallaire, J. Dugat, P. Aitcin. Mechanical properties and durability of two industrial reactive concrete powders. Ait Materials Journal, July-August 1997, p. 286-290.

9. C. Carde. Characterization and modeling of the alteration of properties due to the leaching of cementicious materials. Doctoral thesis, INSA, Toulouse, 1997.

10. M. Cheyrezy. Structural applications of the OPI. Psac conference-AFREM on high-strength concretes and concretes to ultra high performance, INSA Lyon, 3 June 1998.

11. G. Daniel. Composite materials. Hermes edition, Paris 1997.

12. Kumar, Senthil, and Samuel Thavaraj. "Impact of Lean Manufacturing Practices on Clothing Industry Performance." (2015).

13. Munyoro, Gerald, and Fanuel Tinashe Chirimba. "The Contribution of Microfinance to the Development of Rural Farming in Zimbabwe: The Case of Domboshava Rural Farmers."

14. A. Dubey, N. Banthia. Influence of high-reactivity métakaolin and silica smokes on the flexural toughness of high-performance steel fiber-reinforced concrete. Materials Journal, May-June 1998, p. 284-292.

15. A. Tafraoui, S. Lebaili and A. Slimani. Study physico-chemical of the sand of the Western erg of the area of Saoura(Westn south Algeria). Journal of Engineering and Applied Sciences, ISSN:1816-949X, 2007

16. A. Tafraoui, G. Escadeillas, S. Lebaili, T. Vidal. Metakaolin in the formulation of UHPC. Construction and Building Materials. 2009; 23: 669-674.

17. AFNOR, NF EN 12390-5, test for hardened concrete Part 5: resistance to bending on tubes, October 2001

18. Dhoot, Randeep. "The Psychological Approach: A Contribution of Walter Bagehot to Political Theory." (2017).

19. A. Feylessoufi, M. Crespin, P. Dion, F. Bergaya, H. Vandamme. Controlled rate thermal treatment of reactive concrete powder. Advanced cement based materials, vol. 6, 1997, p. 21-27.

20. A. Intes, H. Arnaudin. Characterization of sediments: dimensional criteria and indices, 1987.

21. W. Jean, B. Claude. Composite materials II calculations and tests controls conception. CEP edition, Paris 1983.

22. Y. Malier. The concretes high performance. Presses of the Ecole des Ponts et Chaussées, 1992.

23. A. Messi. Properties of the pozzolanic developed from laterites thermally active. Thesis INSA of Lyon, $1988, p .256$.

24. P. Rougeau, B. Borys. Achieve concrete products to very high performance or fibers at ultra high performance with other ultrafine that silica fume. Document CERIB, Ref. Rfp 114, May 2004.

25. P. Laplante, C. Boulay. Evolution du coefficient de dilatation thermique du b ton enfonction de sa maturit6 aux tout premiers figes. Materials and Structures, 1994, 27, 596-605 